\title{
Corea inducida por Antiparkinsonianos
}

\author{
Pablo Franquelo Morales ${ }^{a}$, Beatriz Valero Serrano ${ }^{a}$, \\ Juan Ramón Toledo Gómeza , Félix González Martínez ${ }^{a}$
}

\begin{abstract}
a Servicio de Urgencias. Hospital Virgen de la Luz. Cuenca.

Correspondencia: Pablo Franquelo Morales, Servicio de Urgencias, Hospital Virgen de la Luz, C/ Hermandad de Donantes de Sangre $n^{\circ} 2$, 16002-Cuenca. E-mail: pfranquelo@yahoo.es.
\end{abstract}

Recibido el 15 de marzo de 2010.

Aceptado para su publicación el 24 de mayo de 2010.

\section{RESUMEN}

La corea constituye un trastorno del movimiento hipercinético caracterizado por movimientos breves, irregulares, rápidos e impredecibles, que cambian de una parte corporal a otra. Puede ser hereditaria, siendo la Enfermedad de Huntington su principal causa, o adquirida, donde los fármacos representan su origen más común en la práctica clínica. La levodopa puede originar corea como una complicación del tratamiento prolongado en pacientes con Enfermedad de Parkinson. Su tratamiento precisa disminución de dosis y control sintomático en función de la intensidad y repercusión funcional de la corea.

Palabras clave. Corea, Agentes Antiparkinsonianos.

\section{ABSTRACT}

\section{Chorea induced by Parkinson's disease treatment}

Chorea is a hyperkinetic movement disorder characterized by brief movements, irregular, rapid and unpredictable changing of a body part to another. It may be hereditary, being Huntington's disease the main cause, or acquired, where drugs represent the most common cause in clinical practice. Levodopa may cause chorea as a complication of prolonged treatment in patients with Parkinson's disease. Its treatment required dose reduction and symptom control in function of the intensity and functional impact of chorea.

Key words. Chorea, Antiparkinson Agents.

\section{INTRODUCCIÓN}

La palabra corea proviene del griego "choreia" que significa danza, y constituye un trastorno del movimiento hipercinético que se caracteriza por movimientos breves, irregulares, rápidos e impredecibles, que cambian de una parte corporal a otra sin una secuencia definida, a menudo descritos como serpentiformes ${ }^{1-3}$. Suelen ser de baja amplitud y localización en la porción distal de las extremidades y cara, aunque también pueden afectar a la parte proximal de éstas y al tronco distal.

No se produce alteración de la conciencia, se exacerban con la ansiedad y la distracción, ceden durante el sueño, y no se controlan con el esfuerzo voluntario ${ }^{4}$. La corea puede ser primaria o hereditaria, siendo la Enfermedad de Huntington $(\mathrm{EH})$ su principal causa ${ }^{5}$, o adquirida, donde los fármacos representan su origen más común en la práctica clínica. La fisiopatología de la corea se basa en una disfunción primaria de los ganglios basales o de las conexiones entre las áreas corticales motoras y, aunque es una condición necesaria para que algunos fármacos la provoquen, otros sin embargo son de por sí "coreogénicos" y no requieren la presencia de esta disfunción $n^{4}$.

\section{OBSERVACIONES CLÍNICAS}

Presentamos a una mujer de 70 años que consultó por cuadro de malestar general con nauseas, vómitos y síntomas de irritación vesical de 3 días de evolución. En tratamiento de larga evolución con espironolactona y captopril por 


\begin{tabular}{|c|c|c|}
\hline $\begin{array}{l}\text { Trastornos neurodegenerativos } \\
\text { hereditarios e idiopáticos }\end{array}$ & $\begin{array}{l}\text { Enfermedad de Huntington } \\
\text { Enfermedad de Wilson } \\
\text { Corea herditaria benigna } \\
\text { Coreatetosis paroxística }\end{array}$ & $\begin{array}{l}\text { Neuroacantocitosis } \\
\text { Ataxias autonómicas dominantes } \\
\text { Atrofia dentatorubro palidoluysiana } \\
\text { Corea senil }\end{array}$ \\
\hline $\begin{array}{l}\text { Enfermedades autoinmunes y } \\
\text { parainfecciosas }\end{array}$ & $\begin{array}{l}\text { Lupus eritematoso sistémico } \\
\text { Corea gravídica } \\
\text { Corea de Sydenham } \\
\text { Esclerosis múltiple } \\
\text { Tétanos } \\
\text { Síndrome antifosfolipídico } \\
\text { Varicela } \\
\text { Artritis Reumatoide }\end{array}$ & $\begin{array}{l}\text { Enfermedad de Bechet } \\
\text { Difteria } \\
\text { Esclerosis múltiple } \\
\text { Púrpura de Shonlein-Henoch } \\
\text { Tos ferina } \\
\text { Panarteritis nodosa } \\
\text { Síndrome de Churg-Strauss }\end{array}$ \\
\hline $\begin{array}{l}\text { Enfermedades metabólicas (congénitas } \\
\text { y adquiridas), mitocondriales, } \\
\text { nutricionales y endocrinológicas. }\end{array}$ & $\begin{array}{l}\text { MELAS } \\
\text { Fenilcetonuria } \\
\text { Enfermedad de Niemann-Pick } \\
\text { Gangliosidosis } \\
\text { Enfermedad de Leigh } \\
\text { Pelagra } \\
\text { Síndrome de Lesh-Nyhan } \\
\text { Síndrome de Kearns-Sayre } \\
\text { Hipertirodismo }\end{array}$ & $\begin{array}{l}\text { Homocistinuria } \\
\text { Enfermedad de Gaucher } \\
\text { Mucopolisacaridosis } \\
\text { Enfermedad de Hartnup } \\
\text { Trastornos electrolíticos } \\
\text { Insuficiencia renal y hepática } \\
\text { Enfermedad de Addison } \\
\text { Encefalopatía de Wernicke } \\
\text { Beriberi }\end{array}$ \\
\hline Lesiones estructurales cerebrales & $\begin{array}{l}\text { ACVAS } \\
\text { Malformaciones vasculares }\end{array}$ & $\begin{array}{l}\text { Tumores } \\
\text { Calcificación de ganglios basales }\end{array}$ \\
\hline Fármacos & $\begin{array}{l}\text { Neurolépticos } \\
\text { Anfetaminas } \\
\text { Cocaína } \\
\text { Anticolinérgicos } \\
\text { Opiáceos } \\
\text { Antagonistas del calcio } \\
\text { Antidepresivos tricíclicos }\end{array}$ & $\begin{array}{l}\text { Aantiparkinsonianos } \\
\text { Antiepilépticos } \\
\text { Anticonceptivos orales } \\
\text { Ciclosporina } \\
\text { Baclofeno } \\
\text { Teofilina } \\
\text { Esteroides }\end{array}$ \\
\hline Tóxicos & $\begin{array}{l}\text { Manganeso } \\
\text { Mercurio } \\
\text { Monóxido de carbono }\end{array}$ & $\begin{array}{l}\text { Talio } \\
\text { Organofosforados } \\
\text { Tolueno }\end{array}$ \\
\hline Neoplasias & $\begin{array}{l}\text { Tumores cerebrales primarios } \\
\text { Metástasis } \\
\text { Linfoma primario de SNC }\end{array}$ & $\begin{array}{l}\text { Leucemia linfoblástica aguda } \\
\text { Anticoagulante lúdico } \\
\text { Síndromes paraneoplasicos }\end{array}$ \\
\hline Asociada a enfermedades neurológicas & $\begin{array}{l}\text { Migraña } \\
\text { Traumatismo craneoencefálico } \\
\text { Enfermedad e Alzheimer } \\
\text { Enfermedad de Pick } \\
\text { Necrosis familiar estriatal } \\
\text { Parálisis cerebral infantil }\end{array}$ & $\begin{array}{l}\text { Parálisis supranuclear progresiva } \\
\text { Atrofia multisitémica } \\
\text { Enfermedad de Pelizaeus- } \\
\text { Merzbacher } \\
\text { Kernícterus }\end{array}$ \\
\hline Asociada a enfermedades sistémicas & $\begin{array}{l}\text { Porfiria aguda intermitente } \\
\text { Sarcoidosis } \\
\text { Anemia falciforme }\end{array}$ & $\begin{array}{l}\text { Policitemia vera } \\
\text { Enfermedad mieloproliferativa } \\
\text { transicional }\end{array}$ \\
\hline Infecciones y parasitosis del SNC & $\begin{array}{l}\text { VIH } \\
\text { Toxoplasmosis } \\
\text { Cisticercosis } \\
\text { Mononucleosis infecciosa } \\
\text { Enfemedad de Creutzfeldt- } \\
\text { Jakob } \\
\text { Enfermedad e Lyme }\end{array}$ & $\begin{array}{l}\text { Sífilis } \\
\text { Fiebre tifoidea } \\
\text { Escarlatina } \\
\text { Enfermedad del legionario } \\
\text { Endocarditis bacteriana }\end{array}$ \\
\hline
\end{tabular}

Tabla 1.Causas de corea secundaria ${ }^{4,7-9}$. 


\begin{tabular}{|c|c|}
\hline Biperideno & $\begin{array}{l}\text { Dosis de } 2-5 \mathrm{mg} \text { iv/im, cada } 30 \text { minutos según eficacia, hasta una dosis máxima de 8-10mg } \\
\text { en } 24 \mathrm{~h} \text {, ó } 2 \mathrm{mg} / 8 \mathrm{~h} \text { vo }\end{array}$ \\
\hline Clonazepam & Dosis inicial de $0,5 \mathrm{mg} / 12 \mathrm{~h}$ vo. Dosis de mantenimiento de $6 \mathrm{mg} / \mathrm{día}$ repartida en $3-4$ tomas \\
\hline Haloperidol & Dosis de 0,5-2 mg/8-12h vo, ó de 2-5 mg/4-6 h iv/im \\
\hline Pimocide & 1-2mg/día vo \\
\hline Tetrabenazina & $\begin{array}{l}\text { Dosis inicial de } 25 \text { mg/día vo repartida en } 2 \text { tomas. Dosis de mantenimiento de } 37,5 \text { mg- } \\
200 \mathrm{mg} / \text { día repartida en } 3 \text { tomas }\end{array}$ \\
\hline Trihexifenidilo & Dosis de $1 \mathrm{mg} / 8 \mathrm{~h}$ vo. Dosis máxima: en adultos $15-25$ mg/día, en niños 40 mg/día \\
\hline Clozapina & $\begin{array}{l}\text { Dosis inicial de } 25 \text { mg/día vo. Dosis de mantenimiento de } 200-300 \text { mg/día repartidas en } 3 \\
\text { tomas }\end{array}$ \\
\hline Risperidona & $\begin{array}{l}\text { Dosis inicial de } 2 \mathrm{mg} / \mathrm{dí} \text { vo repartida en } 2 \text { tomas. Dosis de mantenimiento de } 6-8 \mathrm{mg} / \mathrm{día} \text {, } \\
\text { (dosis máxima de } 12 \mathrm{mg} / \mathrm{día} \text { ) }\end{array}$ \\
\hline Olanzapina & Dosis inicial de 5-10 mg/día vo. Dosis de mantenimiento de $5-20 \mathrm{mg} / \mathrm{día}$ \\
\hline Ziprasidona & $\begin{array}{l}\text { Dosis inicial de } 80 \mathrm{mg} / \mathrm{día} \text { vo repartida en } 2 \text { tomas. Dosis de mantenimiento de } 40 \mathrm{mg} / \\
\text { día repartida en } 2 \text { tomas ó dosis inicial de } 10-20 \mathrm{mg} \text { seguida de } 10 \mathrm{mg} \text { cada } 2 \mathrm{~h} \text { hasta un } \\
\text { máximo de } 40 \mathrm{mg} / \mathrm{día} \leq \text { de } 3 \text { días }\end{array}$ \\
\hline Amantadita & Dosis de 200-300 mg/día vo. Dosis máxima de 400 mg/día \\
\hline
\end{tabular}

Tabla 2. Fármacos utilizados en el tratamiento de la corea ${ }^{8,13}$.

hipertensión arterial e insuficiencia renal crónicas, recibía además asociación de levodopa, carbidopa y entacapona ${ }^{6}$, pramipexol, rasagilina, quetiapina y clonacepan por Enfermedad de Parkinson (EP) de difícil control con fenómenos on-off frecuentes. Recientemente, tras sufrir una caída con traumatismo en la espalda y dolor persistente, se había añadido calcio oral, calcitonina intramuscular y analgésicos a su tratamiento habitual.

Desde hacía 48 horas, y tras toma irregular de antiparkinsonianos, presentaba movimientos involuntarios bruscos generalizados, asincrónicos y anormales de miembros, que afectaban también a ojos y lengua, sin alteración del nivel de conciencia ni fiebre. En la exploración neurológica mostraba un lenguaje normal, pupilas isocóricas y normorreactivas con resto de pares craneales normales. No signos de rigidez ni meningismo.

En las pruebas complementarias se hallaron: $3,4 \times 10^{12} / L$ hematíes, con una hemoglobina de 10,6 $\mathrm{g} / \mathrm{dL}$ y un hematocrito de $31 \%, \mathrm{pH}$ de7.26, $\mathrm{HCO} 3$ $18 \mathrm{mmol} / \mathrm{L}$, urea $167 \mathrm{mg} / \mathrm{dL}$, creatinina $3,2 \mathrm{mg} / \mathrm{dL}$, Ca
$9,4 \mathrm{mg} / \mathrm{dL}, \mathrm{Na} 133 \mathrm{mmol} / \mathrm{L}, \mathrm{K} 5,3 \mathrm{mmol} / \mathrm{L}, \mathrm{LDH} 614$ UI/L y CPK 2232 UI/L. Orina con piuria y bacteriuria abundante con urocultivo en el que creció E. Coli. Electrocardiograma y radiografía de tórax normales.

Se consideró el cuadro como un brote agudo de corea generalizada por sobredosificación de levodopa, facilitada por una insuficiencia renal reagudizada de origen prerrenal en el contexto de una infección urinaria sintomática con rabdomiolisis, también posiblemente relacionada con las inyecciones de calcitonina y el traumatismo previo. Fueron administrados antibióticos y sueroterapia intensiva, y se disminuyó provisionalmente la dosis habitual de levodopa con lo que desapareció la corea. No obstante, en las primeras horas del ingreso y tras incrementar la dosis de levodopa comenzaron a reproducirse los movimientos anteriores, lo que obligó a reintroducirla de una forma más lenta y progresiva. Finalmente se resolvió la insuficiencia renal y la rabdomiolisis, así como la corea, persistiendo al alta con un ligero temblor de reposo. 


\section{COMENTARIOS}

La EH constituye actualmente la causa más importante de corea, sin embargo, existen otras muchas causas que hay que reconocer y tratar precozmente (tabla 1), ya que su diagnóstico correcto puede tener importantes implicaciones pronósticas y terapéuticas. Cuando su comienzo es agudo o subagudo suele ser de origen tóxico ${ }^{1}$, donde una forma relativamente frecuente de presentación es la inducida por fármacos empleados en los pacientes con EP ${ }^{10}$, habitualmente como una complicación del tratamiento prolongado con levodopa ${ }^{11,12}$. No obstante, las complicaciones motoras ocasionadas por este fármaco también se relacionan con la duración y la severidad de la enfermedad, con la dosis administrada, sobre todo altas, con la edad, en la que los jóvenes sufren complicaciones con mayor frecuencia e intensidad, y con la presencia de antecedentes familiares de $\mathrm{EP}^{12}$. Aunque en la mayoría de los casos el cuadro es reversible al retirar el fármaco, su tratamiento requiere suspenderlo de una forma gradual, para evitar la aparición de un Síndrome Neuroléptico Maligno, y reintroducirlo paulatinamente hasta alcanzar las dosis mínimas eficaces, precisando ajustes de dosis en ancianos ${ }^{4}$. No obstante, puede ser necesario el empleo de otros medicamentos para el control de los síntomas motores, psiquiátricos y conductuales, en función de la intensidad y repercusión funcional de la corea (tabla 2).

En conclusión, debemos reconocer a la corea como una importante complicación en los pacientes ancianos y polimedicados que a diario tratamos en nuestras consultas, especialmente con antiparkinsonianos, debiendo ser capaces de identificar el posible fármaco desencadenante para retirarlo, así como tratar las potenciales complicaciones que sucedan.

\section{BIBLIOGRAFÍA}

1. Rayego Rodríguez J, Suárez González F. Corea. Semergen. 2008; 34:308-10.

2. Riverol Fernández M, Luquin Piudo MR. Síndromes hipercinéticos. En: Tratado de Neurología Clínica. Julio Pascual Gómez editor. Madrid: ARS Medica; 2008. p. 539-60.

3. López del Val LJ, Linazasoro Cristóbal G. Concepto, semiología y diagnóstico diferencial de los trastornos del movimiento. En: López del Val LJ, Linazasoro Cristóbal G, editores. Trastornos del movimiento. Madrid: Masson Elsevier; 2002. p. 1-16.

4. Vázquez Sánchez F, Rodríguez Martínez E, Arés Luque A. Actualización en coreas. Rev Neurol. 2009; 48(suppl 1):S11-6.

5. Muñoz García E. Otros trastornos del movimiento: distonía, corea y tics. Medicine. 2003; 8:5102-10.

6. Hauser RA.Levodopa/carbidopa/entacapone (Stalevo). Neurology. 2004; 62(Suppl1):S64-71.

7. Tudurí Pérez I, Liaño Martínez H. Movimientos involuntarios: actualización diagnóstica y terapéutica. FMC. 2001; 8:511-22.

8. Sepúlveda Sánchez JM, Gómez Moreno SM. Trastornos del movimiento. En: Manual de diagnóstico y terapéutica médica" Hospital 12 de Octubre". Carcavilla Martínez AB, Castelbón Fernández FJ, García Sánchez JI, Gracia Lorenzo V, Ibero Esparza C, Lalueza Blanco A, et al, editores. $6^{a}$ edición. Madrid: Merck Sharp \& Dohme de España; 2006. p. 1047-62.

9. Jiménez Jiménez FJ, Alonso Navarro H, Luquin Piudo MR, Burguesa Hernández JA. Trastornos del movimiento: síndromes coreicos y distonía. Medicine. 2007; 9:4741-52.

10. García de Francisco A, García de Francisco S, Prieto Zancudo C. Parkinsonismo inducido por fármacos. FMC. 2002; 9:283-9.

11. Kulisevsky J, Pagonabarraga J. Nuevos tratamientos en lo trastornos del movimiento. Neurología. 2004; 19:4063.

12. Bhidayasiri R, Truong DD. Chorea and related disorders. Post grad Med J. 2004; 80:527-34.

13. Velázquez Pérez JM, Marsal Alonso C. Trastornos del movimiento inducidos por fármacos. Rev Neurol. 2009; 48(Suppl 1): S57-60. 